\title{
Evaluación de parámetros de calidad de diferentes marcas comerciales de leche y yogurt, y cambios durante el almacenamiento
}

\author{
Evaluation of Quality Parameters of Different Trademarks of Milk and Yogurt and Changes \\ During Storage
Catalina Mariel Campos-Salas ${ }^{a}$, José Luis Jiménez-Hernández ${ }^{b}$, Jocelyn Gómez Leyva ${ }^{c}$ Nelly Cruz-Cansino $^{d}$

\begin{abstract}
:
The aims of this study was to analyse the physicochemical properties of different brands of pasteurized milk as well as yogurt in order to evaluate their quality, different brands of pasteurized milk and yogurt were used, two types were obtained: the first was kept in refrigeration for two weeks called "stored sample", the second sample was obtained one day before the tests, called "fresh sample". The results obtained showed that the ALPURA brand has complied with most parameters, nevertheless, does not comply with the pH values obtaining a value of 6.48 where the parameter was 6.5 to 6.8 , regarding to the yogurt, the "fresh" LALA brand obtained a pH of 3.9 being the reference parameter less than 4.4 as well as titratable acidity that represents the best value compared to the other brands analyzed.
\end{abstract}

\section{Keywords:}

Milk, yogurt, specific gravity, non-fatty solids, lactic acid

\section{Resumen:}

El presente estudio tiene como objetivo analizar las propiedades fisicoquímicas de diferentes marcas de leches pasteurizadas así como de yogurt mediante análisis fisicoquímicos con el fin de comprobar su calidad, por lo que se emplearon diferentes marcas de leche pasteurizada y yogurt, de los cuales se obtuvieron dos tipos muestras: la primera se conservó en refrigeración dos semanas denominándose "muestra almacenada", la segunda muestra fue obtenida un día antes de las pruebas, denominándose "muestra fresca". Los resultados obtenidos mostraron que la marca Alpura cumplió con la mayoría de los parámetros, sin embargo, no cumplió con los valores establecidos de $\mathrm{pH}$ (6.5 a 6.8) obteniendo un valor de 6.48, respecto al yogurt, la marca LALA "fresca" obtuvo un pH de 3.9 siendo el parámetro de referencia menor de 4.4 así como en acidez titulable que representa el mejor valor en comparación con las otras marcas analizadas.

\section{Palabras clave:}

Leche, yogurt, gravedad específica, sólidos no grasos, ácido láctico

\footnotetext{
a Autor de Correspondencia, Universidad Autónoma del Estado de Hidalgo, Instituto de Ciencias de la Salud, ORCID: 0000-0002-1033-5117, Email: ca314135@uaeh.edu.mx

${ }^{\mathrm{b}}$ Universidad Autónoma del Estado de Hidalgo, Instituto de Ciencias de la Salud, ORCID: https://orcid.org/0000-0002-0695-0918, Email: ji317166@uaeh.edu.mx

${ }^{c}$ Universidad Autónoma del Estado de Hidalgo, Instituto de Ciencias de la Salud, ORCID: https://orcid.org/0000-0002-4125-6358. Email: josg195@gmail.com

d Universidad Autónoma del Estado de Hidalgo, Instituto de Ciencias de la Salud, ORCID: https://orcid.org/0000-0002-6771-3684, Email: ncruz@uaeh.edu.mx
} 


\section{Introducción}

La leche es la secreción mamaria normal de animales lecheros obtenida a partir de uno o más ordeños sin ningún tipo de adición o extracción, destinada al consumo en forma de leche líquida o a elaboración ulterior, en relación a esto un producto lácteo se define como el obtenido mediante cualquier elaboración de la leche, que puede contener aditivos alimentarios y otros ingredientes funcionalmente necesarios para la elaboración (FAO, 1997).

La composición porcentual promedio de la leche de vaca es: agua $87 \%$, grasa $3.5-3.7 \%$, lactosa $4.9 \%$, proteínas $3.5 \%$ y minerales $0.7 \%$ (Páez y Cols., 2002).

Posterior a la ordeña, la leche es sometida a una serie de ajustes permitidos para mejorar su aspecto y disminuir algunos compuestos para hacerla más atractiva para el consumidor, por ejemplo, los tratamientos térmicos como la pasteurización y ultrapasteurización, el desnatado por centrifugación continua, la homogeneización, fermentación, entre otros, los cuales tienen como fin obtener un producto inocuo, duradero y de alta calidad (Walstra, Geurts, Noomen, Jellema, van Boekel, 2001).

Sin embargo, mediante estos procesos sufre un deterioro en sus propiedades originales a partir de su obtención. Los principales agentes causantes de este deterioro son los microorganismos y las enzimas, las cuales son de origen microbiano 0 propio del alimento. Diversas variables fisicoquímicas del alimento o de su entorno afectan su actividad microbiana y enzimática, por ejemplo, la temperatura, la actividad de agua, el $\mathrm{pH}$, la fuerza iónica, la humedad relativa, entre otros (SEP, 2006).

La calidad de la leche y sus derivados se define como la suma de sus características nutritivas, composicionales, higiénicas, microbiológicas, sensoriales, tecnológicas y fisicoquímica como el $\mathrm{pH}$, acidez titulable, viscosidad, densidad, estabilidad al alcohol, entre otros (Villegas y Santos, 2010).

Uno de sus derivados de interés es el yogurt, el cual es un producto acidificado por medio de un proceso de fermentación llevado a cabo por bacterias lácticas (Walstra, Geurts, Noomen, Jellema, van Boekel, 2001).

El presente reporte tuvo como propósito analizar las propiedades de leche y yogurt tanto frescos como almacenados mediante estudios fisicoquímicos y con ello evaluar la calidad de las marcas para describir los cambios que se generan durante el almacenamiento.

\section{Materiales y métodos}

\section{Obtención de la muestra}

Se utilizó leche pasteurizada y yogurt de las marcas Alpura, LALA y Santa Clara, los cuales fueron adquiridos en diferentes supermercados de la ciudad de Pachuca, Hgo., de los cuales se obtuvieron dos tipos muestras: la primera se conservó en refrigeración por dos semanas, esta se denominó "muestra almacenada", el segundo tipo fue la muestra obtenida un día antes de las pruebas, cuya denominación fue "muestra fresca".

\section{Determinación de densidad de la leche (método de lactómetro de Quevenne)}

para la determinación de la gravedad específica, se colocaron $250 \mathrm{~mL}$ de muestra de leche en una probeta de $500 \mathrm{ml}$, se introdujo el lactómetro, se tomó la lectura y se midió la temperatura. Se corrigió la lectura.

Con la siguiente fórmula se calculó la densidad o gravedad específica:

$$
G E=\frac{\text { Lectura corregida del lactómetro }}{1000}+1
$$

\section{Sólidos totales (ST)}

Utilizando los datos proporcionados de la lectura corregida del lactómetro se calculó el porcentaje de sólidos totales, utilizando la siguiente fórmula:

$$
S T=\left[\begin{array}{c}
\text { Lectura corregida } \\
\text { del lactómetro }
\end{array}\right]+\left[1.2 \times\left(\begin{array}{c}
\% \text { de } \\
\text { grasa }
\end{array}\right)\right]
$$

\section{Sólidos no grasos (SNG)}

De la misma manera se utilizó la lectura corregida del lactómetro para poder sacar el porcentaje de sólidos no grasos por medio de la siguiente fórmula:

$$
S N G=\left[\begin{array}{c}
\text { Lectura corregida } \\
\text { del lactómetro }
\end{array}\right]+\left[1.2 \times\left(\begin{array}{c}
\% \text { de } \\
\text { grasa }
\end{array}\right)\right]
$$




\section{Acidez titulable en leche y yogurt}

Se colocó $9 \mathrm{~mL}$ de muestra en un Matraz de Erlenmeyer de $125 \mathrm{~mL}$, se le agregaron 3 gotas de fenolftaleína al $1 \%$, mientras que al yogurt y a la crema se agregaron 6 gotas. La determinación de la acidez se realizó por titulación $(0.1 \mathrm{~N}$ de $\mathrm{NaOH})$ agitando hasta obtener un rosado intenso.

Para representar el resultado se utiliza la siguiente ecuación:

$$
\% \text { de acidez }=\frac{\left(\begin{array}{c}
m \mathrm{de} \mathrm{NaOH} \\
\text { gastados } \times \mathrm{N} \mathrm{del} \\
\mathrm{NaOH} \times 0.09
\end{array}\right)}{g \text { de muestra }} \times 100
$$

\section{Determinación de porcentaje de grasa}

Se vertió $10 \mathrm{~mL}$ de ácido sulfúrico densidad 1.82 en el butirómetro después se agregó $11 \mathrm{~mL}$ de muestra, se adicionó $1 \mathrm{~mL}$ de alcohol isoamílico, se centrifugó a 1000$1250 \mathrm{rpm}$ durante $5 \mathrm{~min}$ y se tomó la lectura del porcentaje de grasa.

\section{Determinación de pH en leche y yogurt}

Se midió el $\mathrm{pH}$ de la muestra por medio de un potenciómetro marca Oakton.

\section{Análisis estadístico}

Los valores se obtuvieron por triplicado y se analizaron mediante un análisis de varianza (ANOVA) y las diferencias significativas entre las medias $( \pm)$ desviación estándar (DE) fueron comparadas mediante la prueba de Tukey con una $p \leq 0.05$, usando el paquete estadístico SPSS versión 19, para Windows (SPSS Inc. Chicago, Illinois).

\section{Resultados y discusión}

\section{Densidad de leche}

La figura 1 muestra los resultados de diferentes marcas de leche (fresca y almacenada), los rangos de densidad de las muestras se encontraron entre 1.031 y $1.035 \mathrm{~g} / \mathrm{mL}$. La marca Alpura fresca (1.031 \pm 0.0$)$ valores significativamente menores de densidad en comparación con las muestras de Alpura almacenada, LALA fresca y Santa Clara fresca.

La NOM-155-SCFI-2012 establece que el mínimo valor de densidad aceptable es de $1.029 \mathrm{~g} / \mathrm{mL}$ no indicando un valor límite (Norma Oficial Mexicana, NOM-155-SCFI2012), sin embargo el rango propuesto por Código Alimentario Argentino para Leche Entera UHT es de 1.028 a $1.034 \mathrm{~g} / \mathrm{mL}$ (Código Alimentario Argentino, RC33-2006-SPRRS) en referencia al rango de leche pasteurizada donde la muestra de Alpura fresca $(1.031 \mathrm{~g} / \mathrm{mL})$ es la única que cumple con el rango establecido.

En un estudio realizado en Brasil, menciona que los valores de densidad altos en leches almacenadas se deben al proceso de gelificación dados por el aumento de viscosidad y una reducción en los niveles de grasa causada por la actividad de enzimas de la leche o de microorganismos presentes (Longhi y Cols., 2011).

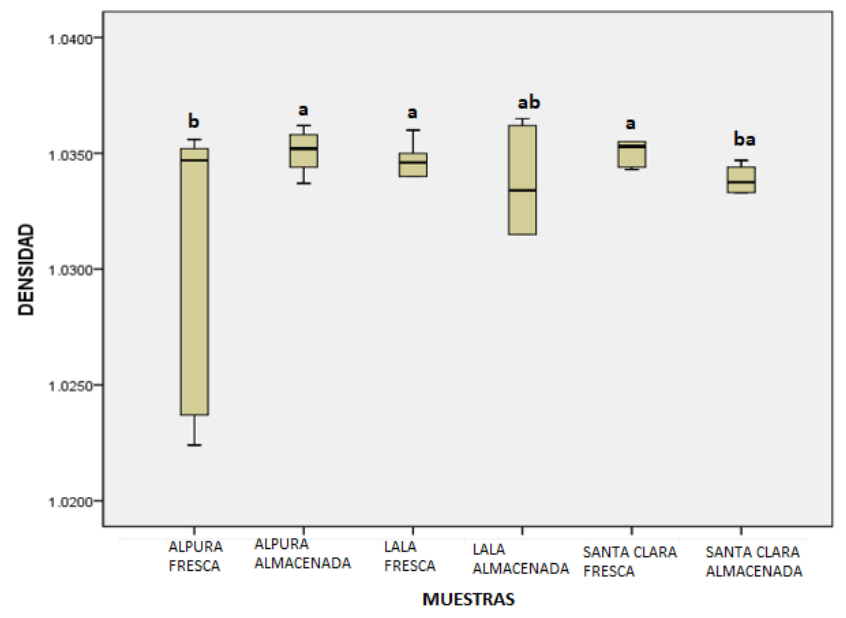

Figura 1. Resultados de densidad de leches frescas y almacenadas. ${ }^{a-b}$ Diferentes letras indican diferencia significativa $(p \leq 0.05)$ entre las muestras.

\section{Sólidos totales}

La figura 2 muestra los valores de sólidos totales de las diferentes marcas de leche fresca y almacenada de entre 12.06 a 12.86 fueron obtenidos. La muestra Santa Clara almacenada obtuvo una diferencia menor $(p \leq 0.05)$ con $12.06 \% \pm 0.15$ en comparación con todas las muestras, excepto Santa Clara fresca.

Los requisitos federales estadounidenses son de $11.25 \%$ mínimo para sólidos totales (Longhi y Cols., 2011) en el estudio ninguna marca de leche resultó con un porcentaje mínimo del establecido.

Motta-Delgado y Cols. (2014) refieren que los sólidos totales de la leche se ven disminuidos por la 
proliferación bacteriana, que de acuerdo con Celis y Juárez (2009) estas ocasionan una serie de modificaciones químicas en la lactosa, proteínas y grasa, sin embargo, ninguna de las muestras almacenadas mostró alteraciones respecto a sólidos totales.

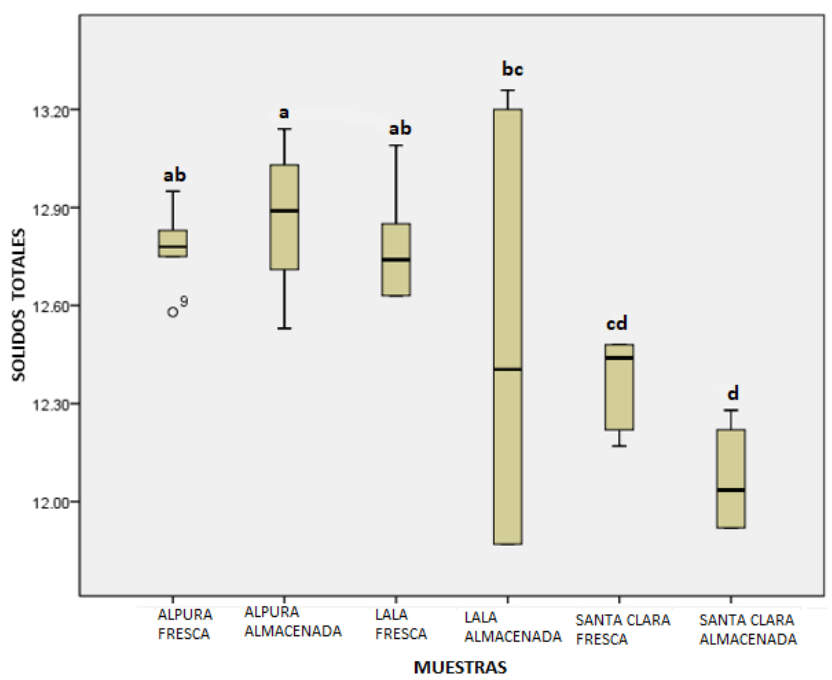

Figura 2. Resultados de sólidos totales. ${ }^{a-d}$ Diferentes letras indican diferencia significativa $(p \leq 0.05)$ entre las muestras.

\section{Sólidos totales no grasos}

Los valores de sólidos no grasos se muestran en la figura 3 , los valores de las diferentes marcas de leche fueron entre 9.06 y 9.45 , la muestra de Santa Clara almacenada presentó diferencia significativa menor $(9.06 \pm 0.15)$ en comparado con la marca de Alpura almacenada $(9.45 \%$ \pm 0.21 .

La NOM-155-SCFI-2012 dicta que el porcentaje mínimo es de $8.3 \%$ (Norma Oficial Mexicana, NOM-155-SCFI2012), todas las muestras de leche fueron mayor a este porcentaje.

Celis y Juárez (2009) indican que la lactosa es degrada a ácido láctico por medio de bacterias lácticas, así como las caseínas pueden ser precipitadas por acción enzimática lo que disminuye la cantidad de sólidos no grasos.

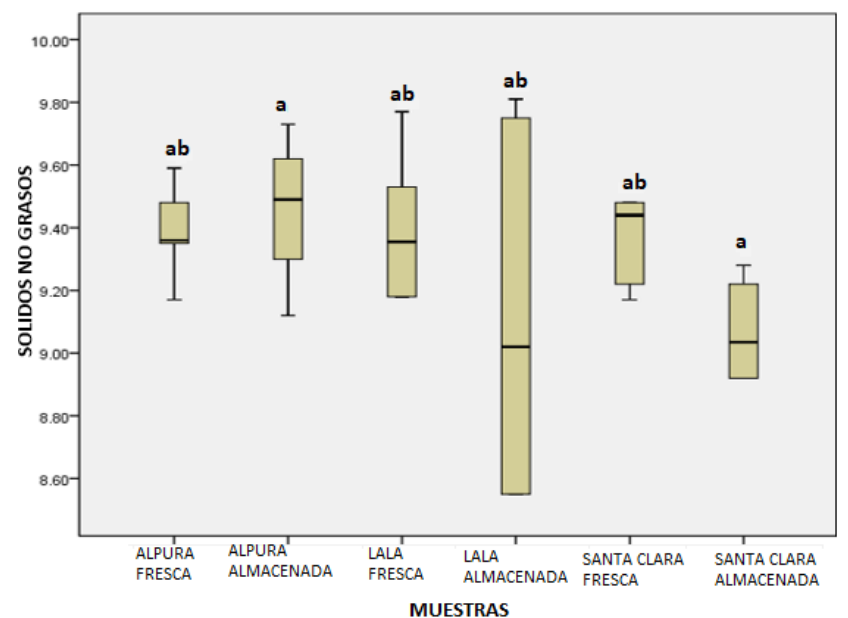

Figura 3. Resultados de sólidos no grasos de leches frescas y almacenadas. ${ }^{a-b}$ Diferentes letras indican diferencia significativa $(p \leq 0.05)$ entre las muestras.

\section{Porcentaje de grasa}

En la figura 4 se muestran los resultados de diferentes marcas de leche (fresca y almacenada) correspondientes a porcentajes de grasa, los valores obtenidos se encontraron entre $3.08 \%$ a $3.76 \%$, la muestra LALA almacenada presentó mayor diferencia significativa $(3.76 \% \pm 0.47)$ respecto a todas las marcas de leche.

La NOM-155-SCFI-2012 indica un porcentaje mínimo de $3 \%$ (Norma Oficial Mexicana, NOM-155-SCFI-2012), en el estudio todas las muestras superan este valor mínimo.

Un porcentaje de grasa menor como en la muestra Santa Clara almacenada puede deberse a lo reportado por Taverna y Cols. (2000) que indican que las lipasas naturales de la leche y microorganismos en especial bacterias psicrotrofas generan lipólisis hidrolizando los lípidos presentes en la leche a ácidos grasos de cadena corta y ácidos grasos laterales. 




Figura 4. Resultados de porcentaje de grasa. ${ }^{a}$ ${ }^{c}$ Diferentes letras indican diferencia significativa $(p \leq 0.05)$ entre las muestras.

\section{Ácido láctico}

Respecto a ácido láctico, los valores se muestran en la figura 5 , obteniendo valores de 0.16 a $0.20 \mathrm{~g} / \mathrm{mL}$. La muestra almacenada de la marca Alpura mostró menores valores con $0.16 \pm 0.01(p \leq 0.05)$ en comparación con la muestra almacenada de Santa Clara.

Según la normativa vigente en Brasil , los rangos de ácido láctico son de 0.14 a 0.18 de acidez expresada en gramos de ácido láctico por $100 / \mathrm{mL}$ (Longhi y Cols., 2011), mientras que la NOM-155-SCFI-2012 indica valores de 0.13 a $0.17 \mathrm{~g} / \mathrm{mL}$ (Norma Oficial Mexicana, NOM-155-SCFI-2012), la muestra de Alpura fresca fue la única marca que se encontró dentro de los rangos normales de acuerdo a la norma.

Así mismo, para la determinación en la leche entera, Longhi y Cols. (2011) mencionan que el aumento de acidez se debe a la degradación de lactosa dado por la acción de microorganismos que convierten una molécula de lactosa, por esta razón la leche Santa Clara almacenada mostró un nivel de ácido láctico mayor de $0.20 \mathrm{~g} / \mathrm{dL}$.

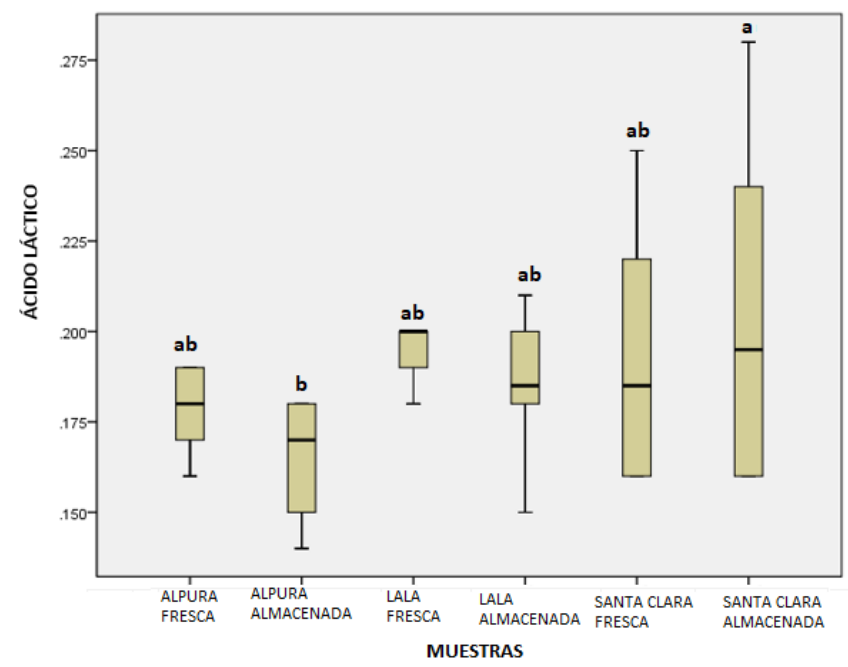

Figura 5. Valores de ácido láctico de leche fresca y almacenada. ${ }^{a-b}$ Diferentes letras indican diferencia significativa $(p \leq 0.05)$ entre las muestras.

\section{pH}

Los resultados de $\mathrm{pH}$ se muestran en la figura 6 , en el estudio el pH entre las muestras se encontró entre 6.48 a 6.65, donde las leches Alpura fresca y almacenada (6.48 \pm 0.09 y $6.48 \pm 0.08$, respectivamente) tuvieron menor diferencia significativa respecto a Santa Clara fresca y LALA almacenada $(6.64 \pm 0.064$ y $6.65 \pm 0.068$, respectivamente).

La NMX-F-446-1984 indica que el rango de normalidad de $\mathrm{pH}$ en la leche es de 6.6 a 6.8 (Norma Mexicana, NMXF-446-1984), las leches Alpura y LALA fresca no obtuvieron un valor dentro del rango el cual es de $6.48 \mathrm{pH}$ y $6.57 \mathrm{pH}$ respectivamente, la leche Santa Clara fresca se encontró dentro del rango con valores de 6.64.

La marca de Alpura almacenada mostró un pH de 6.4 dado por una posible degradación de lactosa, Negril (2005) menciona que las variaciones de $\mathrm{pH}$ dependen del desarrollo de microorganismos que hidrolizan lactosa produciendo ácido láctico dando como resultado una disminución del pH debido a la degradación de la lactosa a varios ácidos orgánicos, especialmente a ácido láctico. 


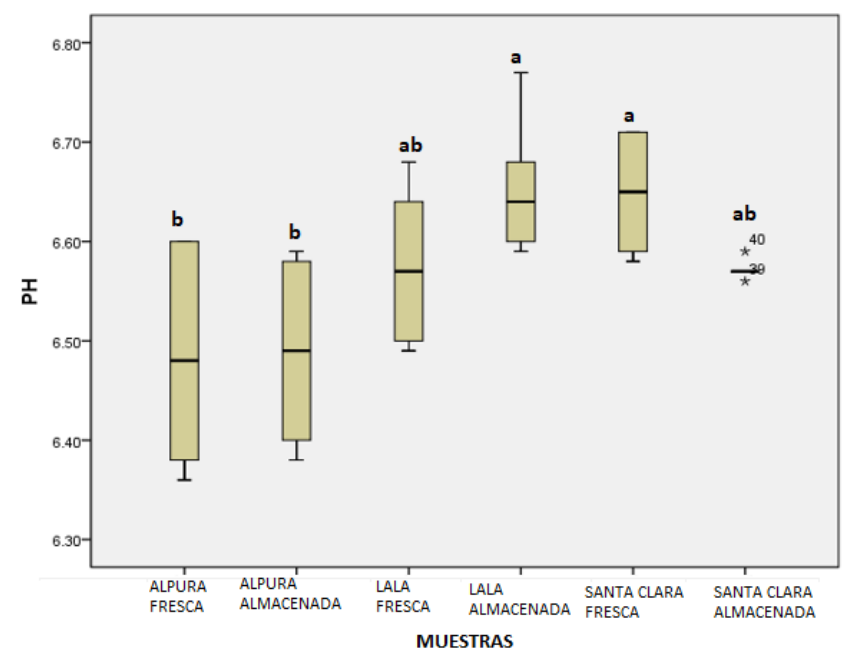

Figura 6. Valores de pH de leche fresca y almacenada. ${ }^{a-b}$ Diferentes letras indican diferencia significativa $(p \leq 0.05)$ entre las muestras.

\section{Ácido láctico de yogurt.}

Según Parra (2010), el ácido láctico es uno de los más importantes producidos por las BAL, este es el primer ácido orgánico funcionalmente versátil utilizado como acidulante/agente buffer de $\mathrm{pH}$ o inhibidor de esporas de bacterias.

Los valores de ácido láctico del yogurt se muestran en la figura 7 , cuyos valores fueron entre 0.94 a $1.10 \%$. Se puede observar que la marca Alpura fresca mostró menor diferencia significativa de ácido láctico de $0.94 \pm 0.17$ en relación con las demás marcas evaluadas.

La NOM-185-SSA1-2002 establece que los productos lácteos fermentados y los productos lácteos acidificados deben presentar una acidez titulable no menos de $0.5 \%$, la cual será expresada en ácido láctico (Norma Oficial Mexicana, NOM-185-SSA1-2002). De acuerdo a esto, ninguna de las marcas presentó niveles bajos de ácido láctico, sin embargo, la marca de yogurt LALA fresca muestra niveles más elevados.

En cambio, las tres muestras almacenadas de yogurt reflejaron niveles altos de ácido láctico por la acción prolongada del cultivo bacteriano, ya que estas disminuyen el $\mathrm{pH}$, estableciendo una relación entre menor pH mayor es el ácido láctico. Muhammad y Cols. (2009) mencionan que durante el almacenamiento hay una continua actividad de beta-glucosidasas y otras enzimas metabólicas bacterianas produciendo la fermentación de la lactosa formando mayores niveles de ácido láctico.

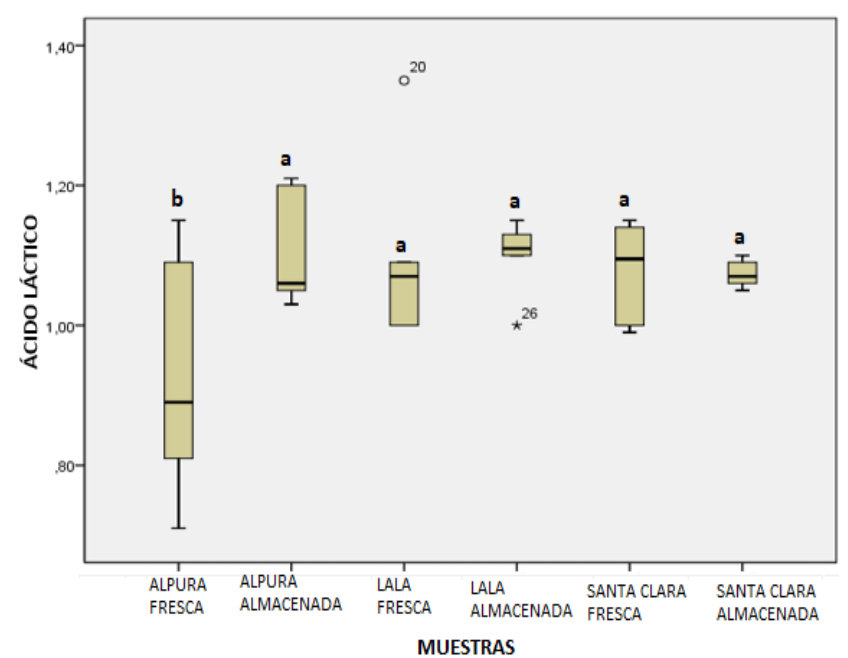

Figura 7. Resultado de ácido láctico de yogurt fresco y almacenado. ${ }^{a-b}$ Diferentes letras indican diferencia significativa $(p \leq 0.05)$ entre las muestras.

\section{pH}

Los valores de $\mathrm{pH}$ obtenidos de las distintas marcas de yogurt se muestran en la tabla 1 , se obtuvieron valores de 3.89 a 4.16. Se puede observar que la muestra almacenada de yogurt LALA arrojó el menor valor $(p \leq 0.05)$ en comparación con las demás marcas.

Para que éstas se encuentren en óptimas condiciones la NOM-185-SSA1-2002 establece que los valores de $\mathrm{pH}$ deben ser <4.4 (Norma Oficial Mexicana, NOM-185SSA1-2002), por lo que se observa que ninguna muestra se encontró por encima de lo establecido. La muestra almacenada y fresca de yogurt LALA ( $3.89 \pm 0.037$ y 3.95 \pm 0.036 , respectivamente) mostraron más bajos de $\mathrm{pH}$.

La disminución de $\mathrm{pH}$ en la muestra de almacenada del yogurt LALA está influenciada por una posible actividad bacteriana, estas bacterias acidificadoras transforman la lactosa a ácido láctico modificando así el pH (Revilla, 1982).

Otro aspecto importante referente a esta disminución de $\mathrm{pH}$, es que tiempo después de la inoculación el $S$. thermophilus inicia la fermentación de lactosa cuando el $\mathrm{pH}$ es neutro liberando ácido láctico, disminuyendo así el $\mathrm{pH}$ lo que estimula el desarrollo del Lactobacillus bulgaricus, este da lugar a la formación de aminoácidos libres como valina, glicina e histidina, los cuales bajan 
aún más el pH estimulando el crecimiento de $S$. thermophilus (González, 2002).

Tabla 1. Valores de $\mathrm{pH}$ de yogurt fresco y almacenado.

\begin{tabular}{lc}
\hline \multicolumn{1}{c}{ Muestra } & pH \\
\hline ALPURA fresca & $4.16 \pm 0.014^{\mathrm{a}}$ \\
ALPURA almacenada & $4.16 \pm 0.019^{\mathrm{a}}$ \\
LALA fresca & $3.95 \pm 0.036^{\mathrm{c}}$ \\
LALA almacenada & $3.89 \pm 0.037^{\mathrm{d}}$ \\
Santa Clara fresca & $4.11 \pm 0.08^{\mathrm{b}}$ \\
\hline Santa Clara almacenada & $4.06 \pm 0.041^{\mathrm{b}}$ \\
\hline $\begin{array}{l}\text { a-d Letras superíndices diferentes } \\
\text { significativa ( } \mathrm{indican} \text { diferencia }\end{array}$
\end{tabular}

\section{Conclusión}

Ante los resultados de los diferentes estudios que se realizaron a distintas marcas de leche, tales como Santa Clara, LALA, y Alpura, y para las mismas marcas en su versión yogurt, se encontró que en la marca LALA fresca y Santa Clara fresca sobrepasaron los parámetros establecidos por las normativas mexicanas de $0.19 \mathrm{~g} / \mathrm{mL}$ de ácido láctico para ambas marcas, lo que refleja que hay una disminución de la calidad de las mismas. Referente a estas marcas de leche la marca Alpura cumplió con la mayoría de los parámetros para calidad de leches, sin embargo, para $\mathrm{pH}$ que es uno de los pocos requisitos que presenta las normativas mexicanas no cumplió debido que presentó un valor de 6.48. En cuanto al yogurt la marca LALA fresca obtuvo un $\mathrm{pH}$ de 3.9, siendo menor que las otras marcas para yogurt, así como en acidez titulable obtuvo $1.10 \%$ siendo mayor que las otras marcas pero que se encuentran en los valores establecidos por las normativas mexicanas. Cabe mencionar que, aun en almacenamiento, las marcas Alpura y LALA no mostraron alteraciones en la mayoría de estos parámetros, a excepción de $\mathrm{pH}$.

\section{Referencias}

1. FAO. (1997) Código de principios referentes a la leche y los productos lácteos.
2. Páez, L. y Cols. (2002) Características fisicoquímicas de la leche cruda en las zonas de Aroa y Yaracal, Venezuela. Rev. Cientif. 12(2), 3-4

3. Walstra, P., Geurts, T.J., Noomen, A., Jellema, A. y van Boekel, M.A.J.S. (2001) Leche. En: Ciencia de la leche y tecnología de los productos lácteos. España: ACRIBIA, S.A. pp. 26-27.

4. SEP. (2006) Leche fermentada En: Elaboración de productos lácteos. México: Trillas. pp. 61.

5. Villegas, A. y Santos, A. (2010) Introducción En: Calidad de la leche cruda. México: Trillas. pp. 9.

6. Norma Oficial Mexicana NOM-155-SCFI-2012, LecheDenominaciones, especificaciones fisicoquímicas, información comercial y métodos de prueba. En: Diario Oficial de la Federación.

7. Código Alimentario Argentino RC-33-2006-SPRRS. Leche.

8. Longhi, R y Cols. (2011) A survey of the physicochemical and microbiological quality of ultra-heat-treated whole milk in Brazil durning their shelf life. Rev. SDT. 65(1), 45-5

9. Motta-Delgado, P.A. y Cols. (2014) Factores inherentes a la calidad de la leche en la agroindustria alimentaria. Rev. Colombiana cienc. Anim. 6(1), 223-242.

10. Celis, M y Juárez, D. (2009) Microbiología de la leche. En: Seminario de procesos fundamentales físico-químicos y microbiológicos. Editorial de la Universidad Tecnológica Nacional. Bahía blanca. p. 4-18

11. Taverna, M. y Cols. (2000) La lipolisis en la leche: Causas, formas de prevención e incidencia sobre la calidad de los productos lácteos. Asocia. Calid. Lech. y Der.

12. Norma Mexicana. NMX-F-446-1984. Alimento para humanos. Leche pasteurizada preferente. En: Dirección General de Normas.

13. Negril, L. (2005) El pH y la acidez de la leche. En: Manual de referencias técnicas para el logro de leche de calidad (2da ed). INTa.

14. Parra, R.A. (2010) Review. Bacterias ácido lácticas: Papel funcional en los alimentos. Facu. Cienc. Agropec. 8(1), 98.

15. NORMA Oficial Mexicana NOM-185-SSA1-2002, Productos y servicios. Mantequilla, cremas, producto lácteo condensado azucarado, productos lácteos fermentados y acidificados, dulces a base de leche. Especificaciones sanitarias. En: Secretaria de Salud.

16. Muhammad, B y Cols. (2009) Effect of period and condition of storge on properties of yogurt produced from cow milk and soymilk materials. Resarch journal of dairy sciences. 3(2), 1824.

17. Revilla, A. (1982) Procesamiento de la leche. En: Tecnología de la leche. Procesamiento, manufactura y análisis. Editor Revilla, A. Costa Rica: IICA. pp. 101-148.

18. González, M. (2002) Tecnología para la elaboración de queso blanco, amarillo y yogurt. SENACYT. 1(1), 15. 